- Communication -

\title{
The Effect of Cation Species on the Anodic Oxidation of Organic Solvent Electrolytes
}

\author{
Minato EGASHIRA,* Shigeto OKADA, and Jun-ichi YAMAKI
}

\author{
Institute of Advanced Material Study, Kyushu University (Kasuga-Koen, Kasuga, Fukuoka 816-8580, Japan)
}

Received February 19, 2001 ; Accepted March 28, 2001

\begin{abstract}
The anodic stability of a series of electrolytes consisting of propylene carbonate (PC) solvent and $\mathrm{BF}_{4}{ }^{-}$anion was shown to be partially influenced by cation species. A lithium cation lowered the anodic stability of electrolytes, particularly when the content of the cation was $1 \mathrm{~mol} \mathrm{dm}^{-3}$ or higher. It was considered that lithium cation had the high ability to coordinate anion species that provided the lower anodic stability. When the interaction between cation and anion was small enough, the higher anodic stability of $\mathrm{BF}_{4}{ }^{-}$anion was observed.
\end{abstract}

Key Words : Anodic Stability, Organic Solvent Electrolyte, ${ }^{19} \mathrm{~F}-\mathrm{NMR}$

\section{Introduction}

Electrolyte solutions are increasingly required to have wide electrochemical windows for application to highperformance energy storage devices, such as $5-\mathrm{V}$ lithium batteries $^{1,2)}$ and electrochemical capacitors. ${ }^{3)}$ The potential limit of an electrolyte depends on the anodic and cathodic reaction rates at a given potential, according to the Butler - Volmer type relationship in the initial state of reaction. It is therefore important to understand the precise mechanism of anodic or cathodic decomposition of electrolytes on an electrode surface.

The anodic oxidation process of such electrolytes has been less studied than the cathodic process ; particular attention has been given to the lithium deposition process and surface studies of lithium negative electrodes for use in lithium batteries. ${ }^{4-6)}$ While studies of new electrolyte systems often utilize anodic stability data, ${ }^{3,7,8)}$ it is difficult to compare such data, because they are usually measured using different methods. Ue et al. showed the anodic stability data of various organic solvent electrolytes with tetraalkylammonium cations. ${ }^{9,10)}$ These basic data are highly informative and are used as a standard of reference in most researches on lithium batteries and double layer capacitors. However, in terms of lithium salt electrolytes, these data seem not to correspond always to a practical anodic behavior of electrolytes. For instance, the anodic behavior of various lithium salt/propylene carbonate (PC) electrolytes measured by Koshiba et al.$^{11)}$ is different in several regards from the anodic behavior of tetraalkylammonium salt electrolytes reported by Ue $e t a l .^{10)}$ The onset of anodic current of lithium salt electrolytes obviously differs by the kind of anion species such as $\mathrm{ClO}_{4}{ }^{-}, \mathrm{CF}_{3} \mathrm{SO}_{3}{ }^{-}, \mathrm{BF}_{4}{ }^{-}$and $\mathrm{PF}_{6}{ }^{-}$, while electrolytes containing each of those anion species except $\mathrm{ClO}_{4}{ }^{-}$shows the identical onset indicating mainly the oxidation of solvent in the latter tetraalkylammonium salt case. It is generally considered that the anodic stability of organic solvent electrolytes depends on the character- istics of anion and solvent species. We suspect that this dependency exists and that there are some interaction between the anion and the cation. Therefore, it is important to consider the influence of cation species on the anodic decomposition of electrolytes.

The present study reveals the effect of cation species on anodic behaviors of organic solvent electrolytes by means of ${ }^{19} \mathrm{~F}-\mathrm{NMR}$ spectroscopy and linear sweep voltammogramography using microelectrodes. Specifically, we investigate tetraalkylammonium tetrafluoroborate/propylene carbonate (PC) systems and lithium tetrafluoroborate/ $\mathrm{PC}$ systems.

\section{Experimental}

The electrolyte solutions used in this study were prepared by dissolving the prescribed amount of tetraethylammonium tetrafluoroborate $\left(\mathrm{Et}_{4} \mathrm{NBF}_{4}\right)$, tetrabutylammonium tetrafluoroborate $\left(\mathrm{Bu}_{4} \mathrm{NBF}_{4}\right)$ (Tomiyama Chemical Co.) and $\mathrm{LiBF}_{4}$ (Morita Chemical Co.) into PC (battery grade; Tomiyama Chemical Co.) in a glove box filled with argon. The solution of $1 \mathrm{~mol} \mathrm{dm}^{-3}$ triethylmethylammonium tetrafluoroborate $\left(\mathrm{Et}_{3} \mathrm{MeNBF}_{4}\right) / \mathrm{PC}$ was purchased from Tomiyama Chemical Co. Most solutions contained less than $30 \mathrm{ppm}$ of moisture as measured using a Karl - Fischer aquacounter (Hiranuma, AQ-7). The electrochemical analysis of these solutions was made using a sealed 3-electrode cell. The working electrode was a platinum microelectrode $(100 \mu \mathrm{m}$ in diameter) and has been described in detail in a previous paper. ${ }^{12)}$ Silver wire was used as a quasi-reference electrode. Under some conditions, similar measurement were done using reference electrode consisting of $\mathrm{Ag} / 0.05 \mathrm{~mol} \mathrm{dm}^{-3}$ of $\mathrm{AgNO}_{3}$ in $\mathrm{PC}$ solution. The current curves obtained using former quasi-reference electrode showed a good correspondence with ones using latter reference electrode, thus we treated $\mathrm{Ag}$ quasi-reference electrode as indicating the $\mathrm{Ag} / \mathrm{Ag}^{+}$equilibrium potential. Platinum plate was used as a counter electrode. The cell was constructed 
within the glove box.

Potential sweep measurement using the cell was carried out using a sweep rate of $0.5 \mathrm{mV} \mathrm{s}^{-1}$ and a potential range from open circuit voltage to a voltage at which the current reached $5 \mathrm{~mA} \mathrm{~cm} \mathrm{~cm}^{-2}$ in the anodic direction. It was confirmed in the previous study that the contribution of the charging current of the electric double layer can be ignored under condition of such a sweep rate. The potential was controlled by a high-sensitivity potentiostat (Fuso Electronics, HECS 318C) equipped with a function generator (Hokuto Denko, HB-104) and a digital recorder (Hioki, 8835). The ${ }^{19} \mathrm{~F}-\mathrm{NMR}$ spectra of electrolyte solutions were measured using a JEOL JNM-LA400 spectrometer with a default internal lock. Hexafluorobenzene was used as a reference.

\section{Results and Discussion}

Figure 1 shows the linear sweep voltammograms obtained in the electrolytes of $\mathrm{Et}_{4} \mathrm{NBF}_{4} / \mathrm{PC}, \mathrm{Bu}_{4} \mathrm{NBF}_{4} / \mathrm{PC}$, $\mathrm{Et}_{3} \mathrm{MeNBF}_{4} / \mathrm{PC}$, and $\mathrm{LiBF}_{4} / \mathrm{PC}$. Concentration of all the electrolytes was $1 \mathrm{~mol} \mathrm{dm}^{-3}$. The anodic stabilities of $\mathrm{Et}_{4} \mathrm{NBF}_{4} / \mathrm{PC}$ and $\mathrm{Bu}_{4} \mathrm{NBF}_{4} / \mathrm{PC}$ appear to be quite similar, and $\mathrm{Et}_{3} \mathrm{MeNBF}_{4} / \mathrm{PC}$ looks slightly more stable than the other two solutions. These three solutions show basically similar anodic behaviors. The $\mathrm{LiBF}_{4}$ salt solution looks unstable over $2.5 \mathrm{~V}$ vs. $\mathrm{Ag} / \mathrm{Ag}^{+}$.

Figure 2 shows the linear sweep voltammograms obtained in $0.01,0.1$ and $1 \mathrm{~mol} \mathrm{dm}{ }^{-3} \mathrm{Et}_{4} \mathrm{NBF}_{4} / \mathrm{PC}$ and $\mathrm{LiBF}_{4} / \mathrm{PC}$ solutions. The onset of anodic currents in $\mathrm{Et}_{4} \mathrm{NBF}_{4}$ salt solutions with 1 and $0.1 \mathrm{~mol} \mathrm{dm}{ }^{-3}$ are in a similar extent, while $\mathrm{LiBF}_{4}$ lowered the anodic stability of the solution around $2.5-2.9 \mathrm{~V}$ vs. $\mathrm{Ag} / \mathrm{Ag}^{+}$when its concentration was $1 \mathrm{~mol} \mathrm{dm}^{-3}$. The anodic stability of $\mathrm{LiBF}_{4} /$ $\mathrm{PC}$ solutions is lower than that of $\mathrm{Et}_{4} \mathrm{NBF}_{4} / \mathrm{PC}$ solutions, even when the concentration of the solutions is $0.1 \mathrm{~mol}$ $\mathrm{dm}^{-3}$. When the solutions were diluted to $0.01 \mathrm{~mol} \mathrm{dm}^{-3}$, the onset of anodic currents shifted much higher potential than concentrated solutions due to the effect of a concentration dependence expected to be observed in the anodic oxidation of $\mathrm{BF}_{4}^{-}$, and both salt solutions yielded identical voltammograms. This result suggests that $\mathrm{PC}$ is anodically further stable than $\mathrm{BF}_{4}{ }^{-}$.

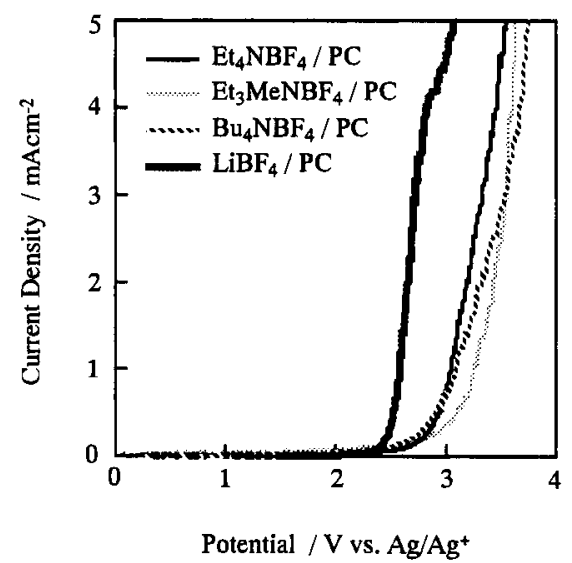

Fig. 1 Linear sweep voltammograms of various PC solvent electrolytes. Sweep rate: $0.5 \mathrm{mV} \mathrm{s}^{-1}$, Electrode: $\mathrm{Pt}, 0.0078$ $\mathrm{mm}^{2}$.

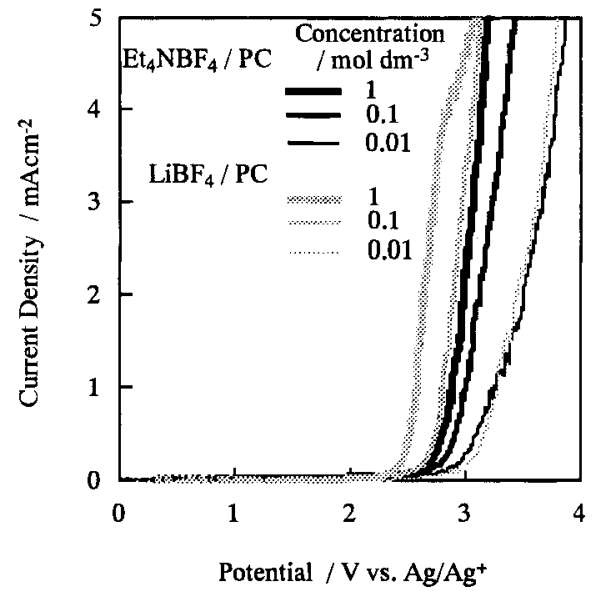

Fig. 2 Linear sweep voltammograms of various PC solvent electrolytes. Sweep rate: $0.5 \mathrm{mV} \mathrm{s}{ }^{-1}$, Electrode: $\mathrm{Pt}, 0.0078$ $\mathrm{mm}^{2}$.

In these cases, the only factor contributing to the difference in anodic stability obtained in $\mathrm{Et}_{4} \mathrm{NBF}_{4} / \mathrm{PC}$ and $\mathrm{LiBF}_{4} / \mathrm{PC}$ was the cation species. It seems likely that the anodic decomposition of the cation itself never becomes a factor on the entire anodic current. The coordination ability of cation species influences the association equilibrium of cation and $\mathrm{BF}_{4}^{-}$; that is, $\mathrm{Li}^{+}$has strong coordination ability ${ }^{13)}$ and may render $\mathrm{BF}_{4}{ }^{-}$unstable by drawing its electron. Figure 3 shows the positions of peaks in ${ }^{19} \mathrm{~F}$-NMR spectra of various concentrations of $\mathrm{Et}_{4} \mathrm{NBF}_{4} /$ $\mathrm{PC}$, and $\mathrm{LiBF}_{4} / \mathrm{PC}$ solutions. In the spectra of both $\mathrm{LiBF}_{4}$ $/ \mathrm{PC}$ and $\mathrm{Et}_{4} \mathrm{NBF}_{4} / \mathrm{PC}$ solutions, only one peak corresponding to fluorine atoms in $\mathrm{BF}_{4}{ }^{-}$was appeared, as expected, besides the peak of internal standard, $\mathrm{C}_{6} \mathrm{~F}_{6}$. The peak appeared at around $12 \mathrm{ppm}$ for $\mathrm{Et}_{4} \mathrm{NBF}_{4} / \mathrm{PC}$ and shifted to a higher magnetic field of $9.5 \mathrm{ppm}$ for $1 \mathrm{~mol}$ $\mathrm{dm}^{-3} \mathrm{LiBF}_{4} / \mathrm{PC}$. In the case of $0.1 \mathrm{~mol} \mathrm{dm}^{-3} \mathrm{LiBF}_{4} / \mathrm{PC}$, the peak appeared at $11.1 \mathrm{ppm}$, and was also shifted from the position in the $\mathrm{Et}_{4} \mathrm{NBF}_{4} / \mathrm{PC}$. It is generally known that an NMR chemical shift originates from a nuclear shield by electron shells. A weaker shield induces higher shifts. As shown in Fig. 3, an electron shell on fluorine nuclei in $1 \mathrm{~mol} \mathrm{dm}^{-3} \mathrm{LiBF}_{4} / \mathrm{PC}$ provided a

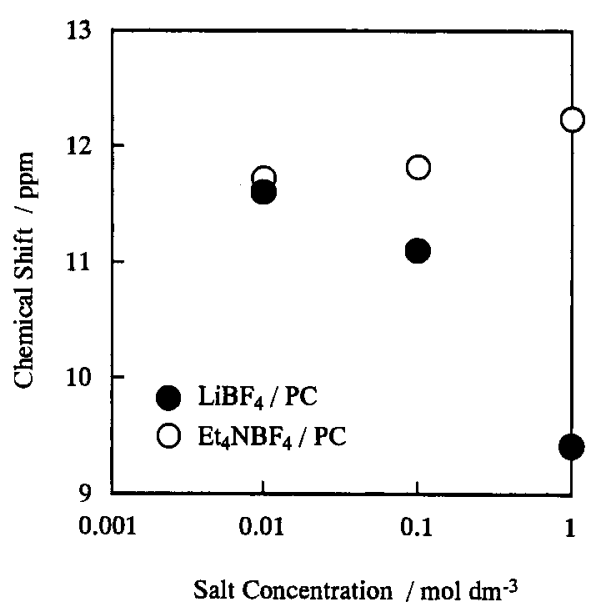

Fig. 3 The changes of peak positions in ${ }^{19} \mathrm{~F}-\mathrm{NMR}$ spectra of various $\mathrm{PC}$ solvent electrolytes. Internal standard : $\mathrm{C}_{6} \mathrm{~F}_{6}$. 
higher shield than that in $\mathrm{Et}_{4} \mathrm{NBF}_{4} / \mathrm{PC}$ or diluted $\mathrm{LiBF}_{4} /$ $\mathrm{PC}$. In other words, the negative charge on $\mathrm{BF}_{4}{ }^{-}$in 1 $\mathrm{mol} \mathrm{dm}{ }^{-3} \mathrm{LiBF}_{4} / \mathrm{PC}$ locates at individual fluorine atoms more than the case in the other solutions. This located negative charge on fluorine atoms is expected to have originated from or help to form a tightly ion pairing from $\mathrm{Li}^{+}$to $\mathrm{BF}_{4}{ }^{-14)}$ Based on their limiting molar conductivity data by $\mathrm{Ue}^{15}{ }^{15}$ the dissociation degrees of $1 \mathrm{~mol} \mathrm{dm}^{-3}$ $\mathrm{LiBF}_{4} / \mathrm{PC}$ and $\mathrm{Et}_{4} \mathrm{NBF}_{4} / \mathrm{PC}$ are roughly estimated to 0.12 and 0.38 , respectively. It seems reasonable that the anodic stability of solutions depends on the amount of tightly bound $\mathrm{LiBF}_{4}$ or $\mathrm{Et}_{4} \mathrm{NBF}_{4}$ ion pairs. It is, however, unclear whether the reactive species is a $\mathrm{LiBF}_{4}$ ion pair, because only one peak appeared even in the spectra of 1 mol dm ${ }^{-3} \mathrm{LiBF}_{4} / \mathrm{PC}$. Therefore, we can only conclude here that an anion strongly coordinated by $\mathrm{Li}^{+}$may become reactive toward the anodic oxidation and accelerate the decomposition of solution according to the mechanism proposed. ${ }^{16)}$ When the solutions were diluted to $0.01 \mathrm{~mol} \mathrm{dm}^{-3}$, the chemical shift positions were slightly moved to higher magnetic field and both salt solutions resulted in the same position. An interaction between $\mathrm{BF}_{4}{ }^{-}$and surrounding solvent molecules may be more effective than that between $\mathrm{Li}^{+}$and $\mathrm{BF}_{4}{ }^{-}$under such a concentration.

The present results support their conclusion, except in the case of the lithium salt solution. A different mechanism must therefore be considered in accounting for the improvement of the anodic stability of lithium salt. For the improvement of the anodic stability of weakly associated electrolytes, an anion or some type of solvent that is intrinsically stable to anodic oxidation must be found. On the other hand, the state of an anion in electrolyte solution must be optimized in the case of lithium salt electrolyte.

\section{Acknowledgement}

The authors thank Prof. Nobuo Kato and Ms. Tomoko
Kinoshita of the Institute of Advanced Material Study, Kyushu University for their help with the ${ }^{19} \mathrm{~F}$-NMR measurement.

\section{References}

1) G. T. -K. Fey, W. Li, and J. R. Dahn, J. Electrochem. Soc., 141, 2279 (1994).

2) H. Kawai, M. Nagata, H. Tsukamoto, and A. R. West, $J$. Mater. Chem., 8, 837 (1998).

3) A. B. McEwen, S. F. McDevitt, and V. R. Koch, J. Electrochem. Soc., 144, L 84 (1997).

4) K. Kanamura, H. Takezawa, S. Shiraishi, and Z. Takehara, J. Electrochem. Soc., 144, 1900 (1997).

5) D. Aurbach, B. Markovsky, A. Shechter, Y. Ein-Eli, and H. Cohen, J. Electrochem. Soc., 143, 3809 (1996).

6) M. Mori, Y. Naruoka, K. Naoi, and D. Fauteux, J. Electrochem. Soc., 145, 2340 (1998).

7) K. Xu and C. A. Angell, J. Electrochem. Soc., 145, L70 (1998).

8) F. Kita, A. Kawakami, J. Nie, T. Sonoda, and H. Kobayashi, J. Power Sources, 68, 307 (1997).

9) M. Ue, K. Ida, and S. Mori, J. Electrochem. Soc., 141, 2989 (1994).

10) M. Ue, M. Takeda, M. Takehara, and S. Mori, J. Electrochem. Soc., 144, 2684 (1997).

11) N. Koshiba, T. Ikehata, and K. Takada, National Technical Report, 37, 64 (1991).

12) M. Egashira, H. Takahashi, S. Okada, and J. Yamaki, J. Power Sources, 92, 267 (2001).

13) U. Olsher, R. M. Izatt, J. S. Bradshaw, and N. K. Dalley, Chem. Rev., 91, 137 (1994).

14) R. Snaith and D. S. Wright, Lithium Chemistry (Eds. A. M. Sapse and P. V. R. Schleyer), John Wiley and Sons, New York, NY, p.273 (1995).

15) M. Ue, J. Electrochem. Soc., 141, 3336 (1994).

16) M. Egashira, S. Okada, and J. Yamaki, submitted to $J$. Power Sources. 